\title{
Impact of Educational Program on Parental Nutritional Social Support among Parents' Female Adolescents
}

\section{ART I CLE IN F O}

\section{Article Type}

Original Research

\section{Authors}

Mokhtari F* $M S c$, Rezaei Adaryani A. ${ }^{1} M D$, Kazemi A. ${ }^{2} P h D$,

Ehsanpour S. ${ }^{3} M S C$

How to cite this article
Mokhtari F, Rezaei Adaryani A,
Kazemi A, Ehsanpour S. Impact of
Educational Program on Parental
Nutritional Social Support among
Parents' Female Adolescents. He-
alth Education and Health Prom-
otion. 2018;6(3):87-90.

*Reproductive Health Department, Nursing \& Midwifery Faculty, Isfahan University of Medical Science, Isfahan, Iran

${ }^{1}$ Radiology Department, Medical Faculty, Isfahan University of Medical Science, Isfahan, Iran

${ }^{2}$ Reproductive Health Department, Nursing \& Midwifery Faculty, Isfahan University of Medical Sciences, Isfahan, Iran

${ }^{3}$ Medical Education Department, Medical Education Research Center, Isfahan University of Medical Sciences, Isfahan, Iran

\section{Correspondence}

Address: Reproductive Health Department, Nursing \& Midwifery Faculty, Isfahan University of Medical Science, Isfahan, Iran. Postal Code: 8174673465

Phone: +98 (31) 37922937

Fax: +98 (31) 36699398

f.mokhtary@ymail.com

\section{Article History}

Received: August 04, 2017

Accepted: June 02, 2018

ePublished: September 09, 2018

\section{A B S T R A C T}

Aims Adolescence is a golden chance for preventing the harms caused by unhealthy behaviors and it is the time for choosing a permanent healthy lifestyle. The aim of study was to evaluate the impact of educational program on parental nutritional social support among parents' female adolescents.

Materials \& Methods The present field trial was conducted from January to May, 2016. Sixtythree female adolescents (33 persons in intervention group and 30 persons in control group) with the age range of 12 to 15 years at schools of Isfahan, Iran, were selected by multistage random sampling method as the samples of the study. Samples were randomly allocated to two groups. Adolescents' perceived and received social support from their parents was measured, using a researcher-made questionnaire, of which the validity and reliability were approved. The intervention included 3 educational sessions (each session took 2 hours) within a one-week interval for adolescents' parents. One month after performing the educational intervention for parents, adolescents' received and perceived social support for having a healthy diet was measured. The data were analyzed, using SPSS 19 and independent $t$ test, paired t test, Chi square, and Mann-Whitney test.

Findings There was no significant difference between two groups regarding the demographic characteristics of the two groups. Also, no significant difference was observed between the two groups after the intervention regarding the mean level of their perceived and received nutritional social support.

Conclusion Educational intervention on parents does not increase perceived and received social support in early adolescents for receiving healthy nutrients.

Keywords Social Support; Parents; Adolescent; Nutrition

\section{CITATION LINKS}

[1] Heightened stress responsiveness and emotional reactivity during pubertal maturation: Implications for psychopathology [2] The relation between intra- and interpersonal factors and food consumption level among Iranian adolescent girls [3] Effect of educational intervention program for parents on adolescents' nutritional behaviors in Isfahan in 2016 [4] Promoting fruit and vegetable consumption. Testing an intervention based on the theory of planned behavior [5] A review of family and social determinants of children's eating patterns and diet quality [6] Multiple sociodemographic and socioenvironmental characteristics are correlated with major patterns of dietary intake in adolescents [7] Psychometric characteristics of the multidimensional scale of perceived social support [8] The development of scales to measure social support for diet and exercise behaviors [9] Association of parental social support with energy balance-related behaviors in low-income and ethnically diverse children: A cross-sectional study [10] Factors influencing adherence to dietary guidelines: A qualitative study on the experiences of patients with type 2 diabetes attending a clinic in Cape Town [11] Joint programming framework for fulfilling the rights of marginalized adolescent girls [12] Gender issues in technology use: Perceived social support, computer self-efficacy and value beliefs, and computer use beyond school [13] The relationship of social support perceived with Student self-efficacy [14] The relationship between perceived social support and selfefficacy among students 


\section{Introduction}

Adolescence is associated with rapid and important physical, mental, and psychological-social changes [1] and increased nutritional needs. If the nutritional needs of adolescents would be fulfilled during this period, it could, along with other environmental factors, lead to decreased possibility of diseases and completing the capacity of development.

Studies have also shown that healthy nutritional behaviors during this period would decrease the possibility of diseases during adulthood. However, the increasing development of unhealthy nutritional behaviors, such as not receiving the necessary nutrients and consuming too much unnecessary and harmful stuff like junk foods, sweetened beverages, and fast foods [2] among adolescents is considered a serious threat for the health of the new generation during adulthood. Therefore, focusing on effective interventions on these behaviors seems inevitable. Furthermore, many health-related behaviors that are established during adolescence would become stable habits during adulthood [3]. Thus, not only adolescence is a golden chance for preventing the harms caused by unhealthy behaviors, but also it is the time for choosing a permanent healthy lifestyle.

In this regard, Rich et al. mentioned that family's participation is an important element in effective educating of students [4]. Parents provide the first level of social support for their children. Many studies have shown that providing necessary nutrients, as a functional social support, is an important predicting structure for nutritional behaviors of children and adolescents $\left[\begin{array}{ll}5,6 & 6\end{array}\right.$. Therefore, interventional programs for increasing parents' social support could affect the adolescents' unhealthy nutritional behaviors; but, since teenagers' behaviors are complicated, the effect of interventional programs must be studied. Therefore, the aim of the present study was to evaluate the effect of an interventional program for improving parents' supportive behaviors to provide a ground for appropriate nutritional behaviors in female adolescents.

The aim of this study was to evaluate the impact of educational program on parental nutritional social support among parents' female adolescents.

\section{Materials and Methods}

The present study was a field trial, which was conducted from January to May, 2016 after the approval of the Ethics Committee of Isfahan University of Medical Sciences. Sixty-three female adolescents (33 persons in intervention group and 30 persons in control group) with the age range of 12 to 15 years at schools of Isfahan, Iran, were selected by multistage random sampling method as the samples of the study. Four schools were randomly selected from the schools of Isfahan and through random allocation; two were selected as the control environment and two as the intervention environment. Samples from each school were randomly selected from the list of students of different grades, using the table of random number. The inclusion criterion for the adolescent included not having any psychological diseases or behavioral disorders and for the parents, it included having the custody of the adolescent. The exclusion criterion was immigration during the study participating in the educational sessions by parents.

The data were gathered, using received and perceived nutritional social support researchermade questionnaire. Zimet et al. [7] inspired the design of this questionnaire from Diet-Specific Social Support for Adolescents (DSSA) [8] and Multidimensional Scale of Perceived Social Support (MSPSS). The questionnaire was based on 5-point Likert scale. This questionnaire measures perceived social support (2 questions) and received social support in 3 dimensions, including instrumental (22 questions), informational (10 questions), and emotional (8 questions). For scoring, the answer of "never" equaled 1 and "always" equaled 5. For reverse questions, "never" equaled 5 and "always" equaled 1. Fourteen questions were reverse.

The designed questionnaire was given to 10 experts in the field of health and nutrition development and after applying their opinions, the validity of the questionnaire was approved. The reliability of the questionnaire was approved with a Cronbach's $\alpha$ of 0.78 and a repeatability coefficient of 0.79 through a pilot study that was conducted on 20 teenagers and repeated after 3 weeks.

Adolescents' parents were invited by phone calls for conducting the study and after taking informed consent from the adolescents and one of their parents, group educational sessions were conducted. Before the first sessions, the adolescents filled perceived received nutritional social support questionnaire. The intervention included 3 educational sessions (each session took 2 hours) within a one-week interval and only the presence of one of the parents was necessary. During the intervention, an educational message was sent to the parents as a reminder every 3 day.

The educational content included training parents about making appropriate communication with their adolescent, the method of presenting trainings to children and the methods of providing social support in 3 dimensions, including informational, emotional, and instrumental; these were all based on a documented educational guide. Educating sessions were held by the help of was slideshow, speech, pamphlets, and group discussions and expressing the experiences by parents.

The control group received education about nutritional knowledge. One month after the last educational session, the adolescents again filled the received and perceived nutritional social support questionnaire. 
The data were analyzed, using SPSS 19 and independent $t$ test, paired $t$ test, Chi square, and Mann-Whitney test. The level of error for all the statistical tests was set at 0.05 .

\section{Findings}

From 70 invited parents of female adolescents, 63 accepted to participate and continue the study to the end. The frequency distribution of fathers' educational level was significantly different between intervention and control groups. In the intervention group, fathers had a higher level of education $(p<0.0001)$, but the samples of the two groups were similar in demographic characteristics. Hence, there was no significant difference between two groups in demographic characteristics (Table 1).

No significant difference was seen while considering the level of perceived and received instrumental, informational, and emotional social support (based on adolescent's point of view) before and after the intervention. In addition, the level of perceived and received social support had no significant difference between the intervention and the control group ( $p>0.05$; Table 2).

Table1) Comparison of demographic characteristics in the intervention $(n=33)$ and control groups $(n=30)$

\begin{tabular}{|c|c|c|c|}
\hline \multicolumn{4}{|c|}{ Variables $\quad$ Control group Intervention group $p$ value } \\
\hline \multicolumn{4}{|c|}{ Mean of age (Year) } \\
\hline Girls & $13.60 \pm 1.16$ & $13.39 \pm 0.93$ & 0.13 \\
\hline Fathers & $46.90 \pm 6.02$ & $43.24 \pm 8.53$ & 0.89 \\
\hline Mothers & $41.47 \pm 6.49$ & $38.15 \pm 7.52$ & 0.36 \\
\hline \multicolumn{4}{|c|}{ Mean of BMI $\left(\mathrm{kg} / \mathrm{m}^{2}\right)$} \\
\hline - & $20.45 \pm 4.74$ & $20.91 \pm 4.13$ & 0.95 \\
\hline \multicolumn{4}{|c|}{ Fathers' educational level (Frequency) } \\
\hline Under diploma & $16(53.3 \%)$ & 0 & \multirow{3}{*}{$<0.0001$} \\
\hline Diploma & $6(20 \%)$ & $20(60.6 \%)$ & \\
\hline Academic & $8(26.7 \%)$ & $13(39.4 \%)$ & \\
\hline \multicolumn{4}{|c|}{ Mothers' educational level (Frequency) } \\
\hline Under diploma & $11(36.6 \%)$ & $8(24.3 \%)$ & \multirow{3}{*}{0.08} \\
\hline Diploma & $11(36.7 \%)$ & $17(51.5 \%)$ & \\
\hline Academic & $8(26.7 \%)$ & $8(24.2 \%)$ & \\
\hline \multicolumn{4}{|c|}{ Economic status (Frequency) } \\
\hline Weak & $19(63.3 \%)$ & $20(60.6 \%)$ & \multirow{2}{*}{0.22} \\
\hline Good & $11(36.7 \%)$ & $13(39.4 \%)$ & \\
\hline
\end{tabular}

Table 2) Comparison of the mean of different dimensions of social support in groups before and after educational intervention

\begin{tabular}{|c|c|c|c|c|}
\hline Variables & $\begin{array}{l}\text { Intervention } \\
\text { group }\end{array}$ & p value & $\begin{array}{l}\text { Control } \\
\text { group }\end{array}$ & p value \\
\hline \multicolumn{5}{|c|}{$\begin{array}{l}\text { Received Social Support } \\
\text { Instrumental }\end{array}$} \\
\hline $\begin{array}{l}\text { Before } \\
\text { After }\end{array}$ & $\begin{array}{l}84.55 \pm 8.51 \\
87.03 \pm 6.52\end{array}$ & 0.11 & $\begin{array}{c}82.07 \pm 9.99 \\
83.90 \pm 12.51\end{array}$ & 0.34 \\
\hline \multicolumn{5}{|c|}{ Informational } \\
\hline $\begin{array}{l}\text { Before } \\
\text { After }\end{array}$ & $\begin{array}{l}41.33 \pm 6.52 \\
41.00 \pm 6.52\end{array}$ & 0.81 & $\begin{array}{l}38.83 \pm 7.32 \\
38.93 \pm 9.02\end{array}$ & 0.92 \\
\hline \multicolumn{5}{|l|}{ Emotional } \\
\hline $\begin{array}{l}\text { Before } \\
\text { After }\end{array}$ & $\begin{array}{l}33.27 \pm 3.26 \\
33.67 \pm 4.22\end{array}$ & 0.61 & $\begin{array}{l}31.83 \pm 5.45 \\
31.87 \pm 6.25\end{array}$ & 0.97 \\
\hline \multicolumn{5}{|c|}{ Perceived Social Support } \\
\hline $\begin{array}{l}\text { Before } \\
\text { After }\end{array}$ & $\begin{array}{l}8.15 \pm 1.28 \\
8.27 \pm 1.35 \\
\end{array}$ & 0.64 & $\begin{array}{l}8.50 \pm 1.70 \\
7.98 \pm 1.65\end{array}$ & 0.05 \\
\hline
\end{tabular}

\section{Discussion}

The aim of the present study was to evaluate the effect of an educational interventional program with emphasis on parents' nutritional social support on the perceived and received social support by femal adolescents. Results showed that educating parents were not able to increase their level of social support from adolescents' point of view. It also made no significant difference in their received nutrients. This result would approve the results of other studies, which have indicated that social support is an important effective variable on nutritional behaviors of different groups [5, 6, 9].

In a study conducted by Ebrahim et al., one of the main barriers for consuming high-fiber foods was lack of family's support [10]. Therefore, the ineffectiveness of the program on adolescents' nutritional behaviors was caused by its ineffectiveness on the level of parents' social support.

It must be noted that in the present study, received social support was evaluated from adolescents' point of view. Also, the nutritional intake of children depends on family's economic condition. About $60 \%$ of the samples in both groups had a low economic condition. It proves the multidimensionality of nutritional behaviors in all age groups. It means low economic condition not only would affect the intake of different food groups, but also it would be effective on applying instrumental social support. Hence, it was observed that the mean score of instrumental social support was lower than other dimensions of social support. Therefore, the comprehensive participation of the government and people is necessary for modifying nutritional behaviors among adolescents and just educating and support are not enough.

In addition, behavior interpretation, especially among adolescents, who have fewer motivations for maintaining their health than the adults [11], would occur slowly and the short interval between education and reevaluation of social support and nutritional behaviors is one of the limitations of this study that could have been effective on the results.

Adolescence is the period of independence and proving individual's identity. Therefore, people would be acting completely different about expressing their parents' support in fulfilling their needs during their adolescence than other periods of life. This matter could have been effective on not expressing their parents' supportive behaviors by adolescents.

Similar to Vekiri and Chronaki [12], Tamani et al. believed that what parents would transfer to their children about their abilities and activities would mostly affect their beliefs about learning and it has less effect on what children would actually do or be capable of [13]. Results of their studies also showed that from all the sources of perceived social support, 
family's support is the only predicting variable for self-efficacy and the more one feels supported but their family, the more they have the sense of selfefficacy. Thus, for improving nutritional behaviors, it seems that interventions should focus on other effective factors in the behavior along with focusing on the improvement of parents' social support and multidimensional design may be more effective for modification of psychological viewpoint of adolescents ${ }^{[14]}$.

Educating parents to provide social support for their adolescent to change or modify their nutritional behavior is not enough; hence, it is recommended that programs about perceiving support for adolescents and intervention for both parents be conducted. Also, nutrition is influenced by habits and cultural factors. Therefore, more comprehensive interventions for longer period is recommended.

\section{Conclusion}

Educational intervention on parents does not increase perceived and received social support in early adolescents for receiving healthy nutrients.

Acknowledgements: This article was adopted from a research approved by Isfahan University of Medical Sciences by No. 394645. The authors would like to thank the research chancellor of the university, principals of schools, parents, and students for their support and cooperation.

Ethical approval: All procedures performed in studies involving human participants were in accordance with the ethical standards of the Ethics Committee of Isfahan University of Medical Sciences and with the 1964 Helsinki declaration and its later amendments or comparable ethical standards. Informed consent was obtained from all individual participants and their parents included in the study.

Conflict of interests: Authors declare that they have no conflict of interest.

Authors' Contribution: Mokhtari F (First author), Introduction author/ Methodologist/ Original researcher/ Discussion author (28\%); Rezaei Adaryani A (Second author), Introduction author/ Methodologist/ Discussion author (24\%); Kazemi A (Third author), Methodologist/ Statistical analyst/ Discussion author (24\%); Ehsanpour S (Fourth author), Introduction author/ Methodologist/ Assistant (24\%).

Funding: Isfahan University of Medical Sciences (grant number 394645) funded this study.

\section{References}

1- Dahl RE, Gunnar MR. Heightened stress responsiveness and emotional reactivity during pubertal maturation: Implications for psychopathology. Dev Psychopathol. 2009;21(1):1-6.

2- Kazemi A, Nekuei Zahraei NS, Nazarian N. The relation between intra- and interpersonal factors and food consumption level among Iranian adolescent girls. Iran J Nurs Midwifery Res. 2016;21(2):147-52.

3- Mokhtari F, Kazemi A, Ehsanpour S. Effect of educational intervention program for parents on adolescents' nutritional behaviors in Isfahan in 2016. J Edu Health Promot. 2017;6:103.

4- Kothe EJ, Mullan BA, Butow P. Promoting fruit and vegetable consumption. Testing an intervention based on the theory of planned behavior. Appetite. 2012;58(3):9971004.

5- Patrick H, Nicklas TA. A review of family and social determinants of children's eating patterns and diet quality. J Am Coll Nutr. 2005;24(2):83-92.

6- Cutler GJ, Flood A, Hannan P, Neumark-Sztainer D. Multiple sociodemographic and socioenvironmental characteristics are correlated with major patterns of dietary intake in adolescents. J Am Diet Assoc. 2011;111(2):230-40.

7- Zimet GD, Powell SS, Farley GK, Werkman S, Berkoff KA. Psychometric characteristics of the multidimensional scale of perceived social support. J Pers Assess. 1990;55(34):610-17.

8- Sallis JF, Grossman RM, Pinski RB, Patterson TL, Nader PR. The development of scales to measure social support for diet and exercise behaviors. Prev Med. 1987;16(6):825-36.

9- Heredia NI, Ranjit N, Warren JL, Evans AE. Association of parental social support with energy balance-related behaviors in low-income and ethnically diverse children: A cross-sectional study. BMC Public Health. 2016;16(1):1182.

10- Ebrahim Z, De Villiers A, T Ahmed. Factors influencing adherence to dietary guidelines: A qualitative study on the experiences of patients with type 2 diabetes attending a clinic in Cape Town. J Endocrinol Metabol Diabetes S Afr. 2014;19(2):76-84.

11- UNFPA, UNICEF. Joint programming framework for fulfilling the rights of marginalized adolescent girls [Internet]. New York City: UNFPA/UNICEF; 2009 [cited 2014 Jan 18]. Available from: https://www.unfpa.org/publications/girl-power-andpotential.

12- Vekiri I, Chronaki A. Gender issues in technology use: Perceived social support, computer self-efficacy and value beliefs, and computer use beyond school. Comput Education. 2008;51(3):1392-404.

13- Tamanai Far MR, Laith $H$, Mansouri N A. The relationship of social support perceived with Student selfefficacy. J Soc Psychol. 2013;2(28):31-39. [Persian]

14- Tamanai Far MR, Leith $H$, Mansouri Nic A. The relationship between perceived social support and selfefficacy among students. J Soc Psychol. 2013;8(28):31-9. [Persian] 